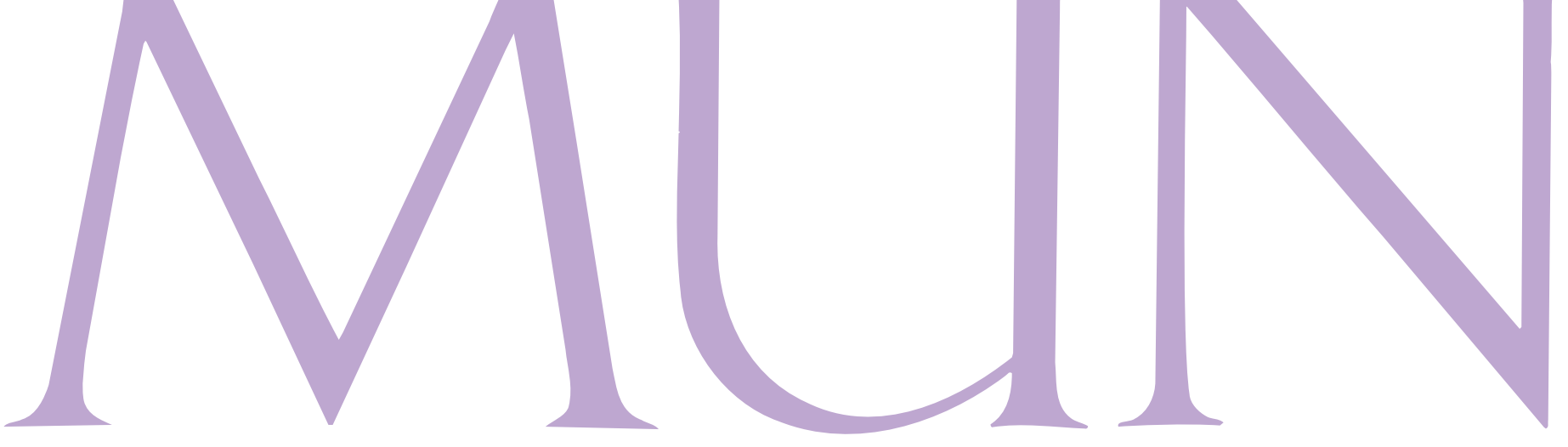

HistóRIA DA CIÊNCIA

\title{
0 progresso da ciência é língua universal de associações pelo mundo
}

Desde a fundação da primeira sociedade para o avanço da ciência, no século XIX, diversas instituições do tipo vêm sendo criadas para promover o diálogo entre cientistas, governos e outras esferas da sociedade civil, isso porque o que deve ser feito com e pela ciência não se restringe apenas a conversas a portas fechadas entre legisladores ou em laboratórios. Para Tom Wang, chefe de relaçôes internacionais da Associação Americana para o Avanço da Ciência (AAAS), criar esse espaço de diálogo é papel crucial de instituiçôes dessa natureza, já que o conhecimento científico não é produzido em uma ilha fora da sociedade em que está inserido. "A interface e a interação entre a comunidade científica e outras áreas da sociedade não é, e não pode ser, apenas resumida à geração do conhecimento científico. De fato, como cidadãos das sociedades onde vivem e trabalham, cientistas são parte do todo social - então essa atividade tem a ver com o engajamento do cientis-

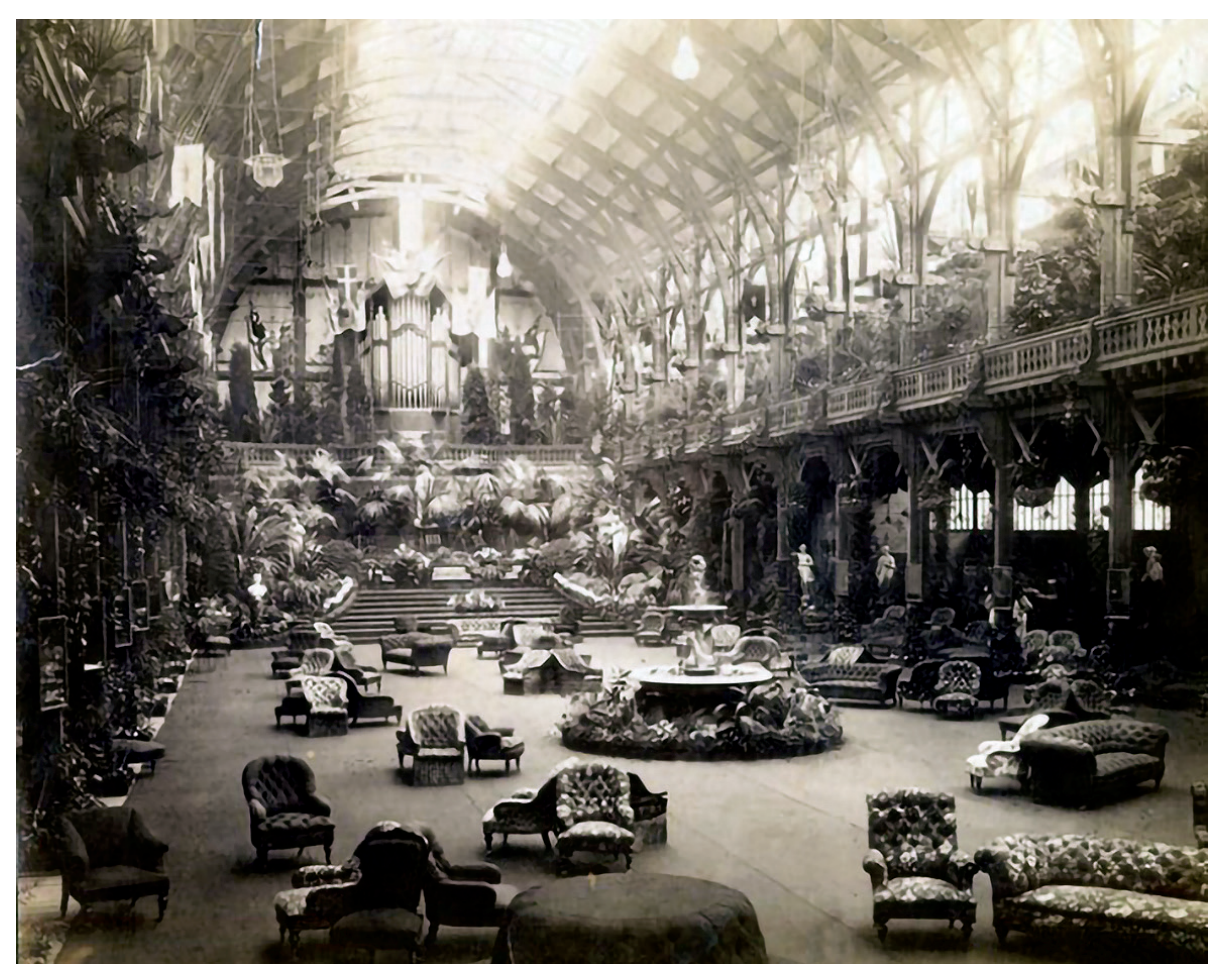

Instituições como a BSA surgiram para facilitar a interação da ciência com a sociedade

ta como indivíduo e como grupo com outras esferas da sociedade". Quando a AAAS surgiu, em meados do século XIX, seu objetivo era congregar cientistas e engenheiros em atividade nos Estados Unidos, em um ambiente multidisciplinar e aberto a cidadãos interessados em ciência. O surgimento da instituição, em 1848 , seguia a tendência do que já estava acontecendo na Europa: em 1822 surgira a primeira associação do tipo - a Sociedade de Naturalistas e Médicos Alemães na cidade de Leipzig - e pouco tempo depois, em 1831, a Associação Britânica para o Progresso da Ciência (atualmente Associação da Ciência Britânica, BSA) em York. Ainda naquela década, em 1839, surgia a Sociedade Italiana para o Progresso da Ciência, em Pisa. Sua congênere francesa veio um pouco mais tarde, em 1872 , em Bordeaux. Índia e Austrália/ Nova Zelândia também criaram suas próprias sociedades nessa época (1876 e 1888, respectivamente). A parte norte do mundo via um crescimento tecnocientífico sem 


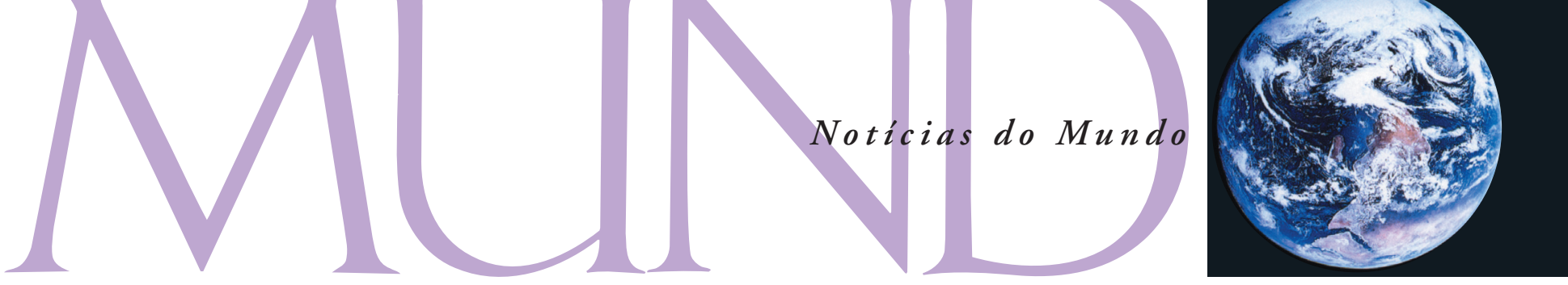

de evidências de base científica para apoiar políticas ambientais". Temas relacionados à imigração também são pauta importante para a AAAS porque "afetam a capacidade de atração de cientistas, estudantes e engenheiros estrangeiros ao país", diz ele.

Já na América Latina, a preocupação com cortes é realidade - e sociedades para o progresso da ciência têm sido bastante atuantes neste sentido. Maria Villaveces, presidente da Associação Colombiana para o Avanço da Ciência, observa que "a força do setor de ciência, tecnologia e inovação não pode ser medida por uma instância burocrática e sim pela produção acadêmica - que não avança se não existe financiamento por parte do setor público em temas estratégicos para o país". Concorda com ela Vanderlan Bolzani, vice-presidente da SBPC: "temos muito desmando. Nosso grande problema é não ter uma política do Estado brasileiro para a ciência, apenas políticas de governo, que ficam à deriva de cada gestão". A SBPC vem se empenhando há tempos no diálogo sobre esse cenário. "Fazemos cartas públicas, não saímos de Brasília... e as verbas continuam sendo tiradas da ciência e da educação. Veja a China: quanto mais percebem uma crise, mais investem em ciência e tecnologia para ficarem mais fortes". E completa: "quando, em um siste-

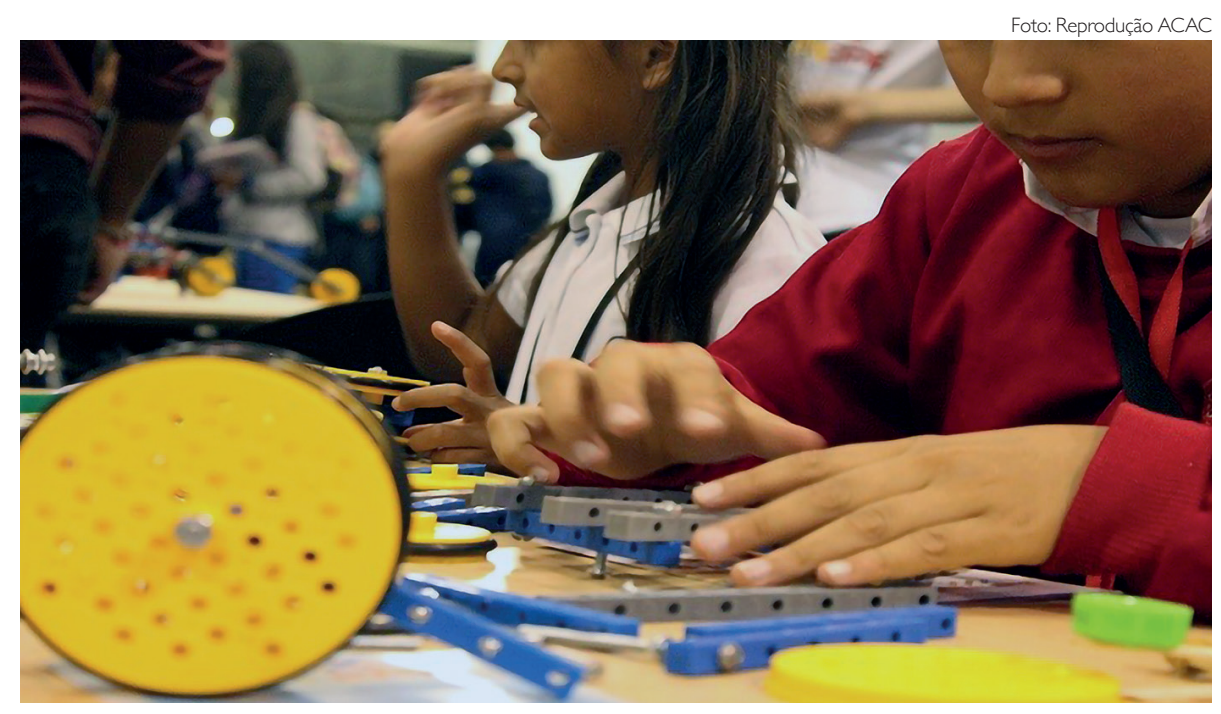

Crianças em evento organizado pela Associação Colombiana para o Avanço da Ciência

ma já abalado, se tira mais dinheiro e se diminui as chances de avanço em pesquisa de excelência para jovens, esta é a morte anunciada de um país".

Longe da América Latina, países árabes também enfrentam desafios de ordem política e econômica para fazer sua ciência progredir. Em 2011, foi criada a Sociedade para o Avanço da Ciência e Tecnologia no Mundo Árabe (SASTA), com sede na Califórnia. Wael Al-Delaimy, presidente da entidade, conta que fundar a SASTA nos EUA foi uma forma de "não associar a instituição com um país árabe específico, correndo o risco de fazer com que outros perdessem o interesse na iniciativa”. Ele explica que a ciência funciona como elemento que traz os países árabes a discussões comuns, mesmo que a diploma- cia, mesmo que científica, não seja uma tarefa fácil de se conseguir no mundo árabe. É uma escada que se vai subindo devagar. "Nosso plano é que os governos abracem a entidade e digam, 'ok, nos ajude a decidir o que fazer' - este é nosso plano, mesmo que seja um país por vez. Damos aconselhamento para universidades - é um passo para o nível nacional e, eventualmente, para o regional". A ambição da SASTA, segundo Al-Delaimy, é ser um ponto de convergência para a ciência árabe - desafio relativamente mais complexo que unir a comunidade científica de um único país. "Queremos que a região se una porque há muito potencial e muita expertise complementar entre os países. Só precisam de alguém que os una”.

Meghie Rodrigues 